\title{
Design and Investigation of Disk Patch Antenna with Quad C-Slots for Multiband Operations
}

\author{
J. A. Ansari, Sapna Verma, and Ashish Singh \\ Department of Electronics and Communication, University of Allahabad, Allahabad, Uttar Pradesh 211002, India \\ Correspondence should be addressed to Sapna Verma; sverma.ece@gmail.com
}

Received 29 July 2014; Revised 21 October 2014; Accepted 9 November 2014; Published 19 November 2014

Academic Editor: Xianming Qing

Copyright (C) 2014 J. A. Ansari et al. This is an open access article distributed under the Creative Commons Attribution License, which permits unrestricted use, distribution, and reproduction in any medium, provided the original work is properly cited.

\begin{abstract}
An investigation into the design and fabrication of multiband disk patch antenna with symmetrically quad C-slots is presented in this paper. The proposed antenna shows multiband resonance frequencies which highly depend on substrate thickness, dielectric constant, and radius of the disk patch. By incorporating two pairs of $\mathrm{C}$-slots in optimum geometry on the radiating patch, the proposed antenna operates between 2 and $12 \mathrm{GHz}$ at different frequency bands centered at 2.27, 7.505, 9.34, 10.33, and 11.61 GHz. The other antenna parameters are studied like gain, antenna efficiency, and radiation pattern. The proposed antenna may find applications in S-, C-, and X-band. The results are carried out with the aid of HFSS and MOM-based IE3D simulator. The measured and simulated results are in good agreement with each other.
\end{abstract}

\section{Introduction}

There is increasing demand for antennas having compact size and multiband operation. Since each communication protocol may operate in a distinctive frequency band, instead of using several antennas, it is highly desirable to have one broadband or multiband antenna to meet the needs of multiple systems. Microstrip disk patch antennas are suitable for many wireless communication applications and frequency bands such as S-band (2-4 GHz), C-band (4-8 GHz), and Xband $(8-12 \mathrm{GHz})$. In addition, compact size with multiband operation is a demand factor for several applications such as mobile communication. The demand of multiband antennas is fulfilled by integrating the diode switches, cutting slots of different geometries, multiple narrow slits in rectangular patch antenna, slot antenna with edge-fed, compact fork shaped antenna, and compact slot on the radiating patch [14]. There are some other techniques reported in literature to obtain multiband behaviour of the antennas such as employing the two microstrip line feeds placed in orthogonal directions [5] and circular ring antenna with a defected ground plane excited by Y-shape-like microstrip feed [6]. Recently, it has been shown that multiband resonance can be achieved by using edge feeding in two circular slots each having T-shaped patch which highly depends on the diameter [7] and cutting two pairs of orthogonal narrow slits on stacked circular disk [8]. However, some of these antenna structures involve complex calculation, sophisticated design structures, and large size as compared to proposed antenna.

In this paper, a quad C-slots disk patch antenna optimized for simplicity in design is proposed for multiband operation. The numerical analysis and geometry refinement of the proposed antenna structure are performed by using method of moment (MOM) based IE3D and finite element method (FEM) based HFSS simulator $[9,10]$. A measured result shows that the proposed antenna is able to operate in multiband. The details of antenna design and simulated as well as measured results are carefully examined and discussed in the following sections.

\section{Antenna Structure}

Figure 1 shows the top view and side view of the proposed antenna.

The disk patch antenna is printed on a $1.6 \mathrm{~mm}$ thick inexpensive FR4 dielectric substrate of relative permittivity of 4.4 and loss tangent of 0.02 . The radius of the probe fed patch antenna is $R=15.0 \mathrm{~mm}$. This antenna provides 


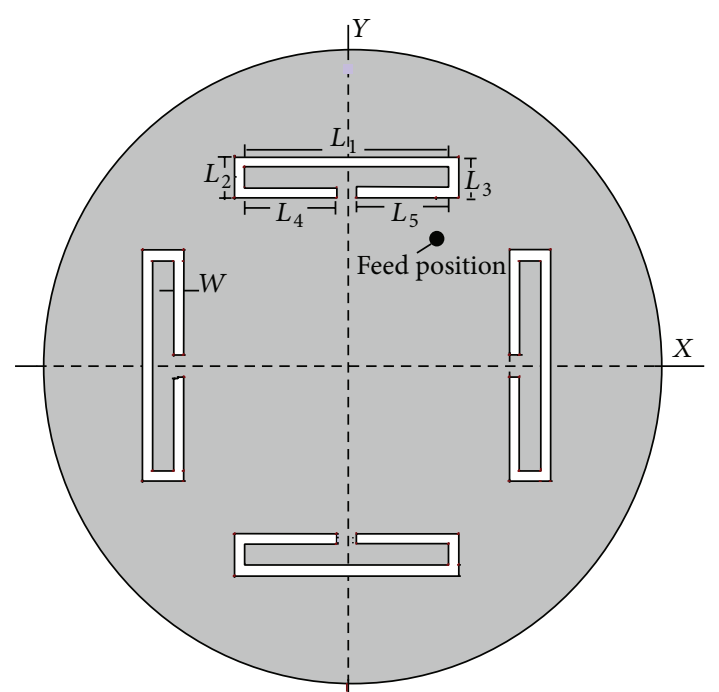

(a)

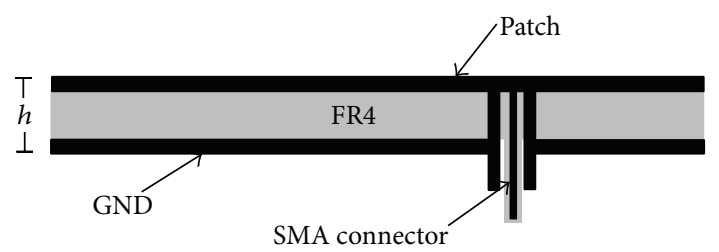

(b)

FIGURE 1: Geometry of the disk patch antenna with quad symmetrical C-slots. (a) Top view of the proposed antenna. (b) Side view of the proposed antenna.

the multiband operation due to the quad symmetrical Cslots etched on the edge of the radiating patch. The optimal parameters of the $\mathrm{C}$ - and inverted C-slots are kept equal. The $L_{1}=11.0 \mathrm{~mm}, L_{4}=L_{5}=5.0 \mathrm{~mm}$, and $L_{2}=L_{3}=2.0 \mathrm{~mm}$ are horizontal and vertical slots of the proposed antenna, respectively. The $W=0.5 \mathrm{~mm}$ is the width of the horizontal and vertical slots of $\mathrm{C}$ - and inverted C-slots.

Theoretically the effect of embedded C-slots on disk patch can be approximately obtained by the impedance of a short dipole via well-known Babinet's principle [11, 12] given as

$$
Z_{\text {slot }} \cdot Z_{\text {dipole }}=\frac{\eta_{0}^{2}}{4}
$$

$$
\begin{aligned}
& Z_{\text {dipole }} \\
& \quad \approx f_{1}(\beta l)-j\left(120\left(\ln \frac{2 L}{W}-1\right) \cot (\beta l)-f_{2}(\beta l)\right), \\
& f_{1}(\beta l) \\
& \quad=-0.4787+7.3246(\beta l)+0.3963(\beta l)^{2}+15.613(\beta l)^{3}, \\
& f_{2}(\beta l) \\
& \quad=-0.4456+17.0082(\beta l)-8.6793(\beta l)^{2}+9.6031(\beta l)^{3},
\end{aligned}
$$

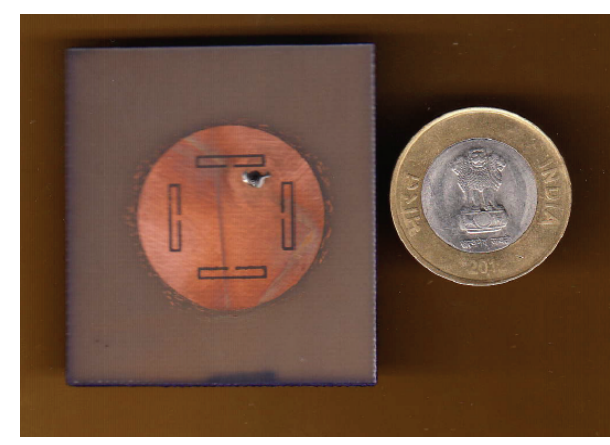

FIGURE 2: Fabricated photo of the proposed antenna.

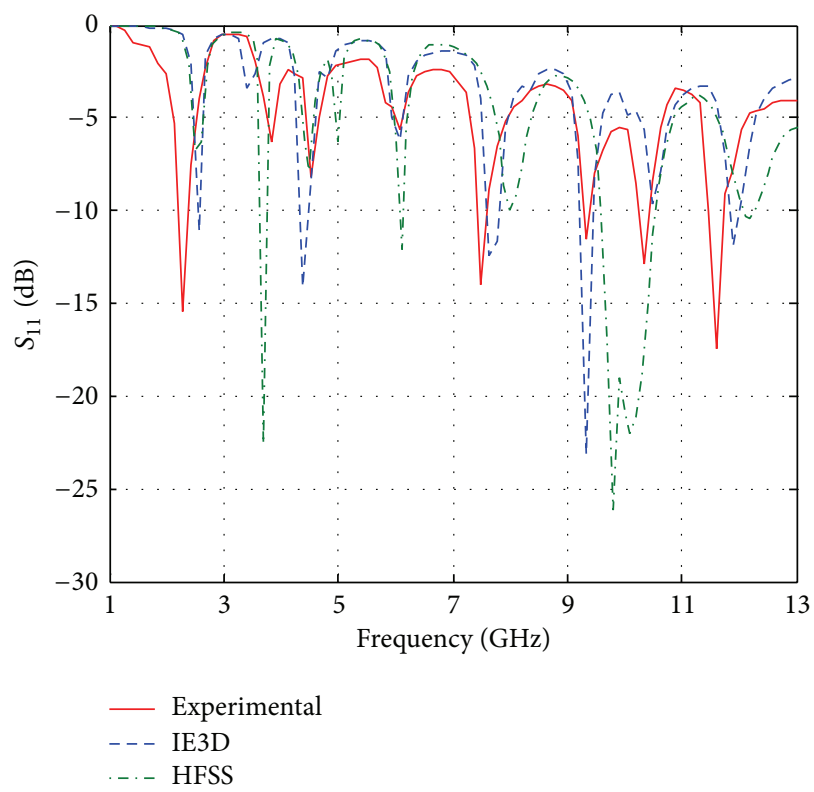

FIGURE 3: Simulated and measured $S_{11}$ of proposed antenna.

where $\eta_{0}=120 \pi, L=$ length of the dipole, and $W=$ width or diameter of the dipole.

\section{Results and Discussion}

A photograph of the fabricated quad C-slots loaded disk patch antenna is shown in Figure 2. The Agilent E5071C Network Analyzer is used to measure the measured $S_{11}$ of the proposed antenna and the simulation performed by IE3D and HFSS simulator. The measured and simulated $S_{11}$ parameters of the proposed antenna are compared as shown in Figure 3, which exhibit good agreement and meet the $-10 \mathrm{~dB}$ requirement in most resonance frequencies that are 2.27, 7.505, 9.34, 10.33, and $11.61 \mathrm{GHz}$. An important feature of the proposed antenna is capable of impedance matching at five resonance frequencies by cutting one by one quad C-slots without changing the feeding point and any other dimensions on the disk patch antenna.

It is observed that the proposed antenna has multifrequency characteristics. This happens due to the slots inserted on the radiating patch. In the first case, first C-slot is cut on 
the radiating patch which gives two resonating frequencies. In the second case, second C-slot loaded to the patch which produces third resonating frequency. Thereafter in the next two steps, three and four C-slots are inserted and the four and five resonance frequency bands were observed. Thus, the slots play vital role in obtaining multiband.

The multiband nature of the proposed structure is found to be confirmed by the fabricated results with some errors within the acceptable limits.

Apparently, the measured return loss below $-10 \mathrm{~dB}$ bandwidths ranges from 2.17 to $2.41 \mathrm{GHz}, 7.38$ to $7.64 \mathrm{GHz}, 9.21$ to $9.485 \mathrm{GHz}, 10.19$ to $10.45 \mathrm{GHz}$, and 11.46 to $11.75 \mathrm{GHz}$ with the relative bandwidth of $10.45 \%, 3.46 \%, 2.94 \%, 2.51 \%$, and $2.498 \%$, respectively, which show the approximate agreement with the simulated results. The differences may be due to the effect of the SMA connector and mismatching tolerance.

The first resonance frequency band operates under the S-band, second resonance frequency band operates at Cband, and third, fourth, and fifth resonance frequency bands operate at X-band.

\section{Parametric Study and Discussion}

Figure 4 shows the variation of $S_{11}$ versus frequency for different values of radius $(R)$ of the quad C-slots loaded disk patch antenna. When other parameters of the antenna $W=0.5 \mathrm{~mm}, L_{1}=11.0 \mathrm{~mm}, L_{2}=2.0 \mathrm{~mm}, L_{3}=$ $2.0 \mathrm{~mm}, L_{4}=5.0 \mathrm{~mm}$, and $L_{5}=5.0 \mathrm{~mm}$ are fixed, it is observed that the resonance frequencies are shifting towards the lower frequency side with increasing the value of radius and corresponding bandwidths are $5.865 \%(3.31-3.51 \mathrm{GHz})$, $2.73 \%(4.34-4.46 \mathrm{GHz}), 3.0 \%(7.53-7.76 \mathrm{GHz}), 2.72 \%$ (9.05$9.3 \mathrm{GHz})$, and $2.06 \%(11.53-11.77 \mathrm{GHz})$. On the other hand, the resonance frequencies are shifting towards the upper frequency side with decreasing the value of the radius of the proposed antenna and corresponding bandwidths are $3.11 \%(3.48-3.59 \mathrm{GHz}), 4.09 \%(4.31-4.49 \mathrm{GHz}), 3.06 \%$ $(7.72-7.96 \mathrm{GHz}), 2.63 \%(9.38-9.63 \mathrm{GHz})$, and $1.48 \%(12.04-$ $12.22 \mathrm{GHz}$ ). It is also observed that when the resonance frequencies are shifting to the lower and upper side, there are some changes in impedance bandwidths.

The variation of $S_{11}$ versus frequency for different values of the substrate thickness is shown in Figure 5, when other parameters $R=15.0 \mathrm{~mm}, W=0.5 \mathrm{~mm}, L_{1}=11.0 \mathrm{~mm}, L_{2}=$ $2.0 \mathrm{~mm}, L_{3}=2.0 \mathrm{~mm}, L_{4}=5.0 \mathrm{~mm}$, and $L_{5}=5.0 \mathrm{~mm}$ are fixed of the antenna.

It is observed that when the value of substrate thickness increases, the resonances are shifting to the upper frequency side and corresponding bandwidths are 9.52\% (2.5$2.75 \mathrm{GHz}), \quad 5.95 \% \quad(4.4-4.67 \mathrm{GHz}), \quad 3.26 \% \quad(7.84-8.1 \mathrm{GHz})$, $3.02 \%$ (9.45-9.74 GHz), and 1.879\% (12.12-12.36 GHz). Similarly, when the value of substrate thickness decreases, the resonance is shifting to the lower frequency side and corresponding bandwidths are $4.37 \%(4.02-4.2 \mathrm{GHz}), 3.73 \%$ $(7.35-7.63 \mathrm{GHz}), \quad 3.05 \% \quad(9.04-9.32 \mathrm{GHz}), \quad 1.064 \% \quad(10.28-$ $10.39 \mathrm{GHz})$, and $2.475 \%(11.57-11.86 \mathrm{GHz})$.

Figure 6 shows the variation of $S_{11}$ versus frequency for different values of relative permittivity $\left(\varepsilon_{r}\right)$, when other

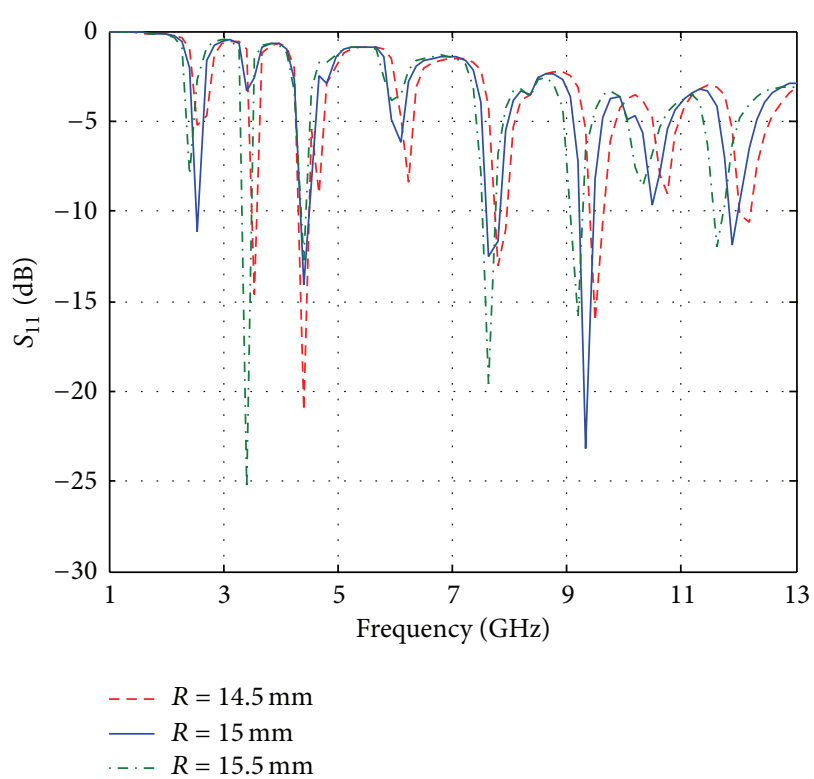

FIGURE 4: Simulated variation of $S_{11}$ versus frequency for different values of radius of the disk $(R)$.

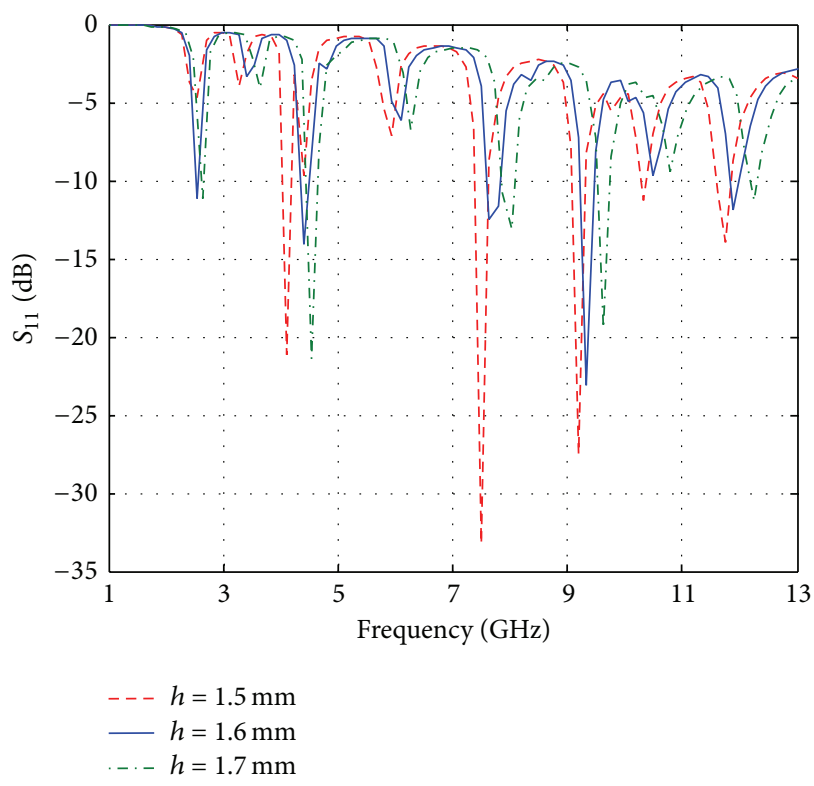

FIGURE 5: Simulated variation of $S_{11}$ versus frequency for different values of substrate thickness $(h)$.

parameters $R=15.0 \mathrm{~mm}, h=1.6 \mathrm{~mm}, W=0.5 \mathrm{~mm}$, $L_{1}=11.0 \mathrm{~mm}, L_{2}=2.0 \mathrm{~mm}, L_{3}=2.0 \mathrm{~mm}, L_{4}=5.0 \mathrm{~mm}$, and $L_{5}=5.0 \mathrm{~mm}$ are fixed of the antenna. Figure shows the multiband behaviour when dielectric constant is high, that is, 4.4 , which gives the five operating bands with bandwidths that are $9.07 \%(2.42-2.65 \mathrm{GHz}), 5.675 \%(4.28-4.53 \mathrm{GHz})$, $6.60 \%(7.32-7.82 \mathrm{GHz}), 2.99 \%(9.2-9.48 \mathrm{GHz})$, and $2.09 \%$ $(11.78-12.03 \mathrm{GHz})$. The rest of dielectric values 2.3 and 1.07 give the single and dual band operation, respectively.

Figure 7 shows the frequency versus gain plot for proposed antenna. From this figure, the measured and simulated 


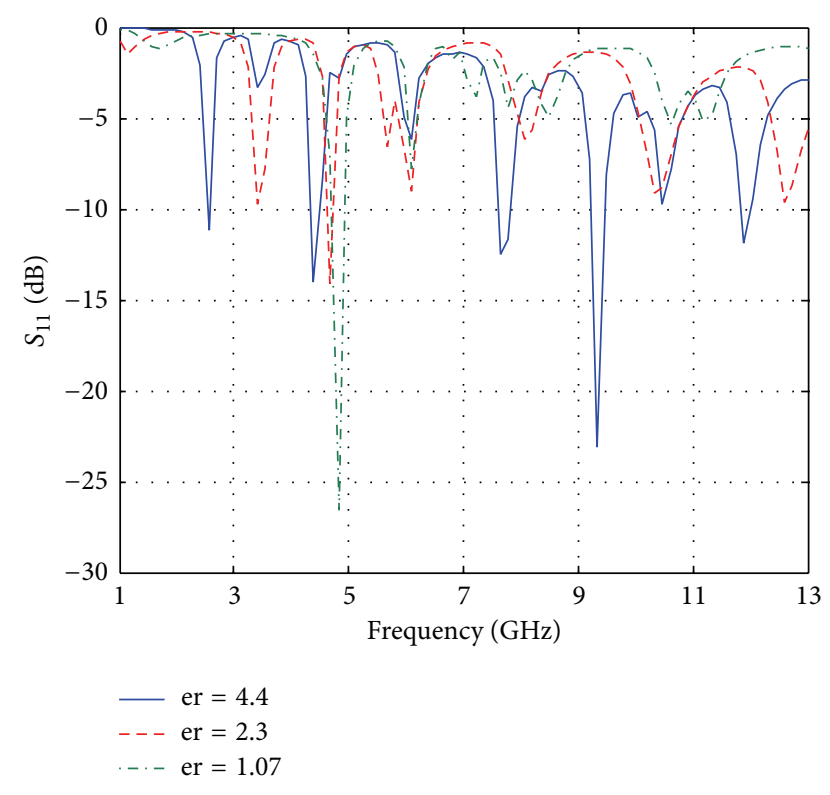

FIGURE 6: Simulated variation of $S_{11}$ versus frequency for different values of substrate material (er).

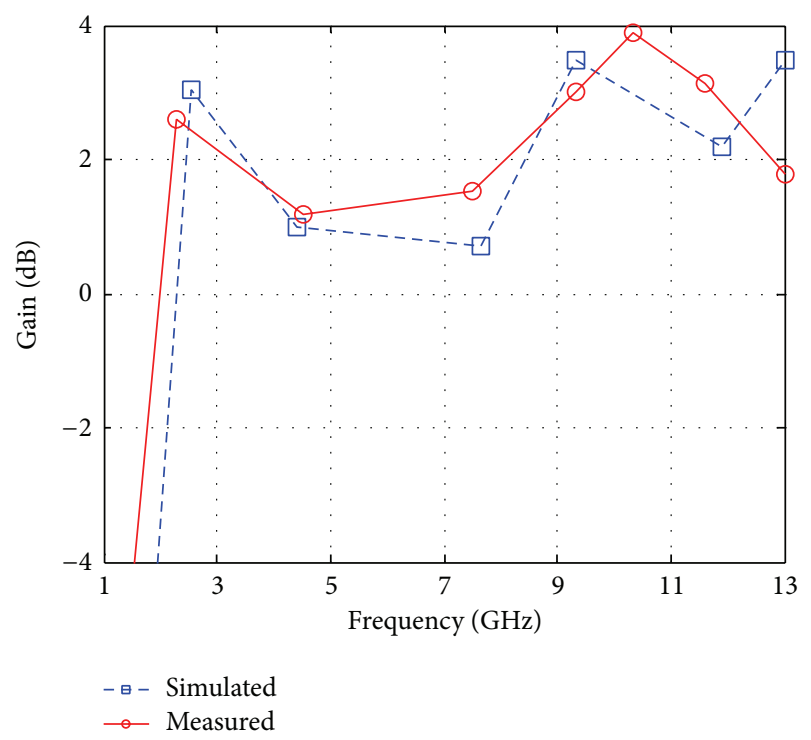

FIGURE 7: Simulated and measured gain at the various frequencies.

gain values at all of the frequencies are shown in figure. The antenna gains are $2.598,1.518,3.015,3.877$, and $3.121 \mathrm{dBi}$ at the five resonant frequencies that are 2.27, 7.505, 9.34, 10.33, and $11.61 \mathrm{GHz}$, respectively. The simulated gains are in good agreement with measured results. Most of the gain variations observed here are less than $1 \mathrm{~dB}$ and these slight differences of antenna gains can be attributed to the effects of conductor and dielectric loss.

The comparative plot of simulated and measured antenna efficiency for the proposed antenna is shown Figure 8. From this figure, the simulated and measured results of the antenna efficiency are in good agreement with each other. It is

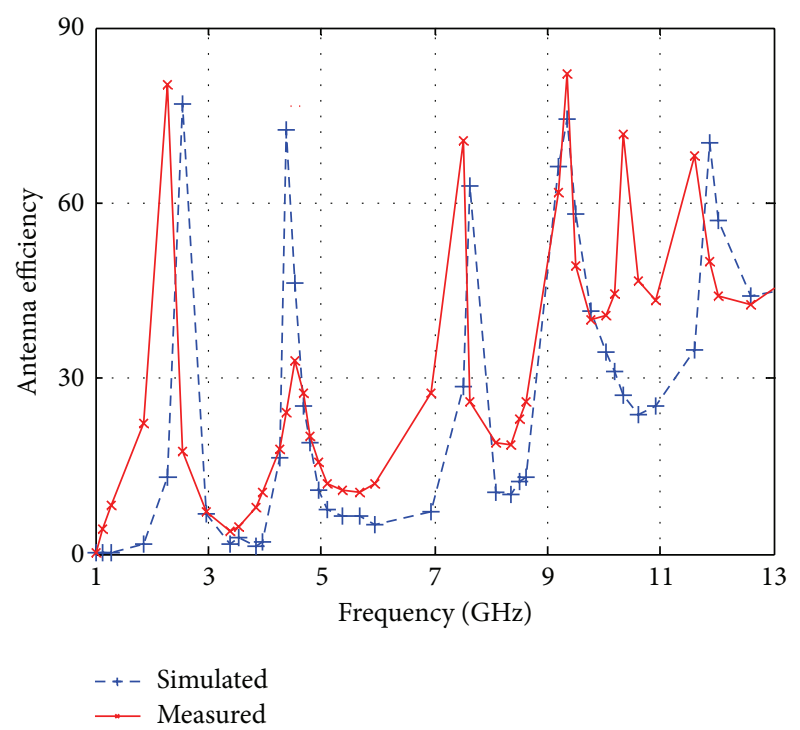

FIGURE 8: Simulated and measured antenna efficiency at the various frequencies.

observed that efficiencies of proposed C-slot loaded disk patch antenna are $80.2 \%, 70.67 \%, 81.91 \%, 71.92 \%$, and $68.15 \%$ at five resonance frequencies that are 2.27, 7.505, 9.34, 10.33, and $11.61 \mathrm{GHz}$, respectively. The radiation pattern of the proposed multiband microstrip antenna is also investigated.

Figure 9 shows the measured and simulated radiation pattern of the antenna at five resonance frequencies 2.27, $7.505,9.34,10.33$, and $11.61 \mathrm{GHz}$. It is observed that measured and simulated results are in close agreement. Results are plotted for $E_{\theta}, \varphi=0^{\circ}$ in $x$ - $z$ plane, and $E_{\theta}, \varphi=90^{\circ}$ in $x$ $y$ plane. Higher order modes are considered because higher order harmonics does not decay much as it can be observed from Figures 9(c)-9(e), which is for 9.34, 1033, and $11.61 \mathrm{GHz}$, respectively.

\section{Conclusion}

The characteristics of a multiband patch antenna with symmetrically quad C-slots have been proposed and verified with simulation and measurement. From the analysis, it is clear that the performance of proposed antenna depends on substrate thickness, radius of the disk patch, and different dielectric material. In proposed antenna, the $\mathrm{C}$ - and inverted C-slots play an important role in controlling resonant frequencies and bandwidth of the antenna and achieving the multiple resonant operations. The proposed antenna can provide sufficient bandwidths along with the moderate gain. This antenna is capable of satisfying the requirements of S-, $\mathrm{C}$-, and X-frequency band.

\section{Conflict of Interests}

The authors declare that there is no conflict of interests regarding the publication of this paper. 


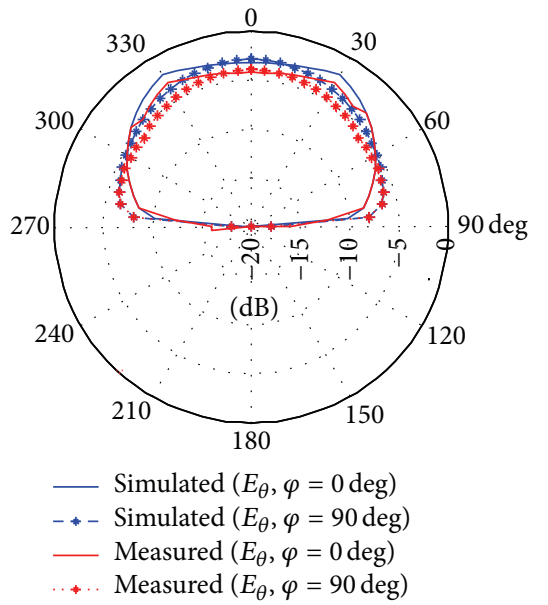

(a) $2.27 \mathrm{GHz}$

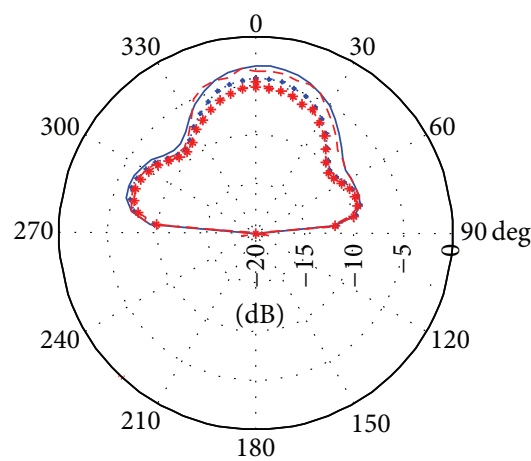

- Simulated $\left(E_{\theta}, \varphi=0 \mathrm{deg}\right)$

..... Simulated $\left(E_{\theta}, \varphi=90 \mathrm{deg}\right)$

- - - Measured $\left(E_{\theta}, \varphi=0 \mathrm{deg}\right)$

$\rightarrow \rightarrow$ Measured $\left(E_{\theta}, \varphi=90 \mathrm{deg}\right)$

(c) $9.34 \mathrm{GHz}$

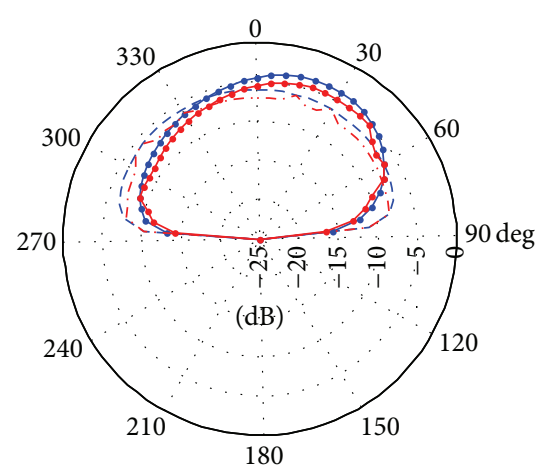

$\longrightarrow$ Simulated $\left(E_{\theta}, \varphi=0 \mathrm{deg}\right)$

- - - Simulated $\left(E_{\theta}, \varphi=90 \mathrm{deg}\right)$

$\longrightarrow$ Measured $\left(E_{\theta}, \varphi=0 \mathrm{deg}\right)$

-. Measured $\left(E_{\theta}, \varphi=90 \mathrm{deg}\right)$

(b) $7.505 \mathrm{GHz}$

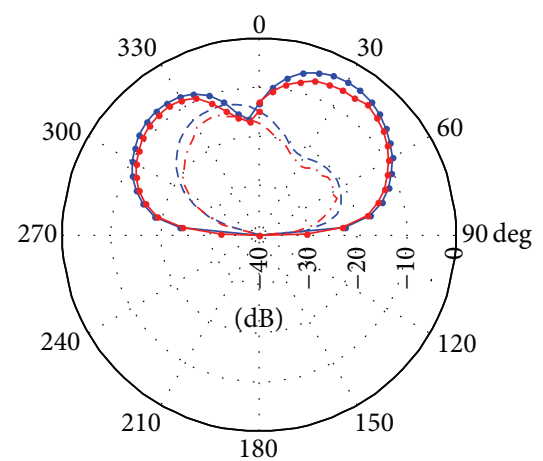

$\longrightarrow$ Simulated $\left(E_{\theta}, \varphi=0 \mathrm{deg}\right)$

- - - Simulated $\left(E_{\theta}, \varphi=90 \mathrm{deg}\right)$

$\rightarrow$ Measured $\left(E_{\theta}, \varphi=0 \mathrm{deg}\right)$

... Measured $\left(E_{\theta}, \varphi=90 \mathrm{deg}\right)$

(d) $10.33 \mathrm{GHz}$

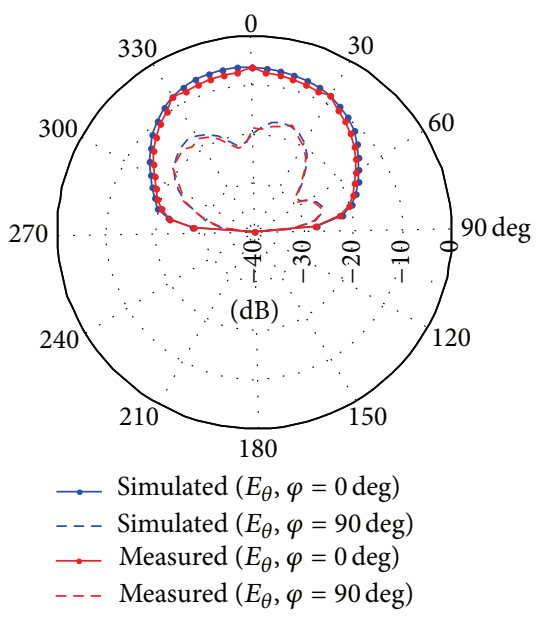

(e) $11.61 \mathrm{GHz}$

FIGURE 9: Simulated and measured radiation pattern at the various frequencies. 


\section{Acknowledgment}

Sapna Verma is also grateful to University Grant Commission (UGC), India, for providing financial assistance (SRF).

\section{References}

[1] D. N. Elsheakh, H. A. Elsadek, E. A. Abdallah, M. F. Iskander, and H. Elhenawi, "Reconfigurable single and multiband inset feed microstrip patch antenna for wireless communication devices," Progress in Electromagnetics Research C, vol. 12, pp. 191201, 2010.

[2] S. Verma, J. A. Ansari, and M. K. Verma, "A novel compact multi-band microstrip antenna with multiple narrow slits," Microwave and Optical Technology Letters, vol. 55, no. 6, pp. 1196-1198, 2013.

[3] L. Xu, Z. Y. Xin, and J. He, "A compact triple-band forkshaped antenna for WLAN/WiMAX applications," Progress in Electromagnetics Research Letters, vol. 40, pp. 61-69, 2013.

[4] L. Dang, Z. Y. Lei, Y. J. Xie, G. L. Ning, and J. Fan, "A compact microstrip slot triple-band antenna for WLAN/WiMAX applications," IEEE Antennas and Wireless Propagation Letters, vol. 9, pp. 1178-1181, 2010.

[5] J. P. Thakur, J.-S. Park, B.-J. Jang, and H.-G. Cho, "Small size quad band microstrip antenna," Microwave and Optical Technology Letters, vol. 49, no. 5, pp. 997-1001, 2007.

[6] J. Pei, A.-G. Wang, S. Gao, and W. Leng, "Miniaturized tripleband antenna with a defected ground plane for WLAN/ WiMAX applications," IEEE Antennas and Wireless Propagation Letters, vol. 10, pp. 298-301, 2011.

[7] X. Sun, G. Zeng, H.-C. Yang, Y. Li, X.-J. Liao, and L. Wang, "Design of an edge-fed quad-band slot antenna for GPS/ WIMAX/WLAN applications," Progress in Electromagnetics Research Letters, vol. 28, pp. 111-120, 2012.

[8] S. K. Gupta, A. Sharma, B. K. Kanaujia, S. Rudra, R. R. Mishra, and G. P. Pandey, "Orthogonal slit cut stacked circular patch microstrip antenna for multiband operations," Microwave and Optical Technology Letters, vol. 55, no. 4, pp. 873-882, 2013.

[9] Zeland Software, IE3D Simulation Software, Version 14.05, Zeland Software, 2008.

[10] “HFSS simulator version 12," Ansoft Corporation, Pittsburg, Pa, USA.

[11] Y. I. Huang and K. Boyle, Antenna from Theory to Practice, John Wiley \& Sons, 2008.

[12] M. Kominami, D. M. Pozar, and D. H. Schaubert, "Dipole and slot elements and array on semi-infinite substrate," IEEE Transactions on Antennas and Propagation, vol. 33, no. 6, pp. 600-607, 1985. 

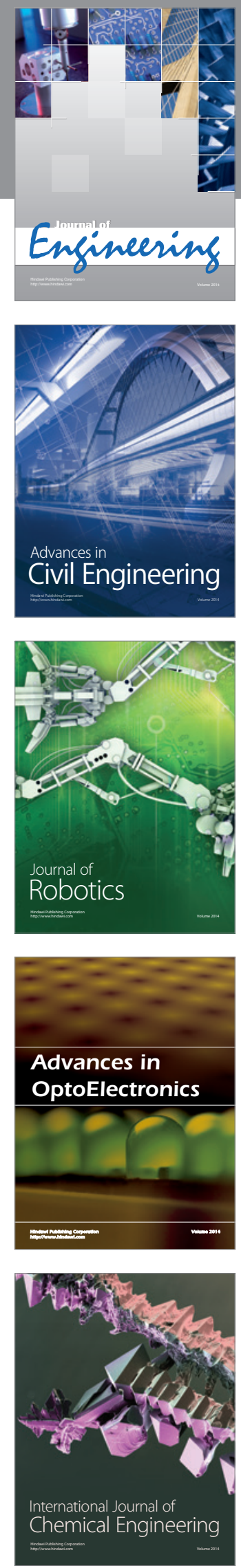

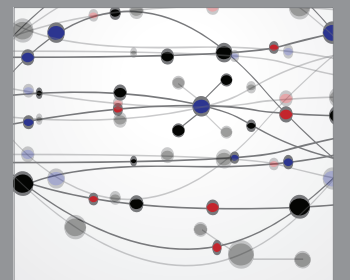

The Scientific World Journal
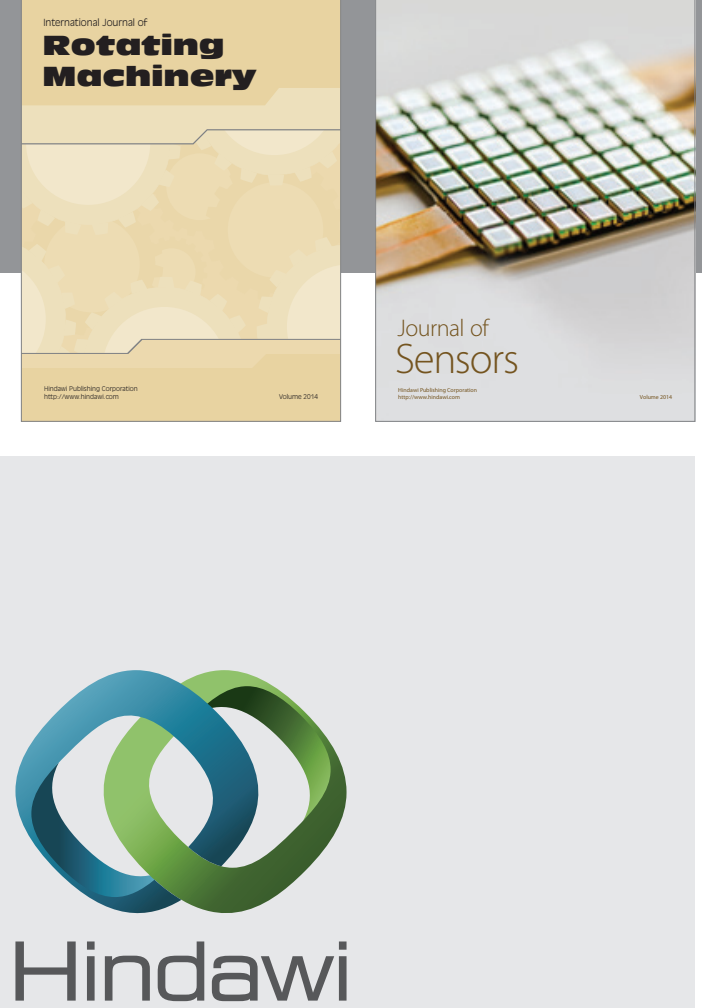

Submit your manuscripts at http://www.hindawi.com
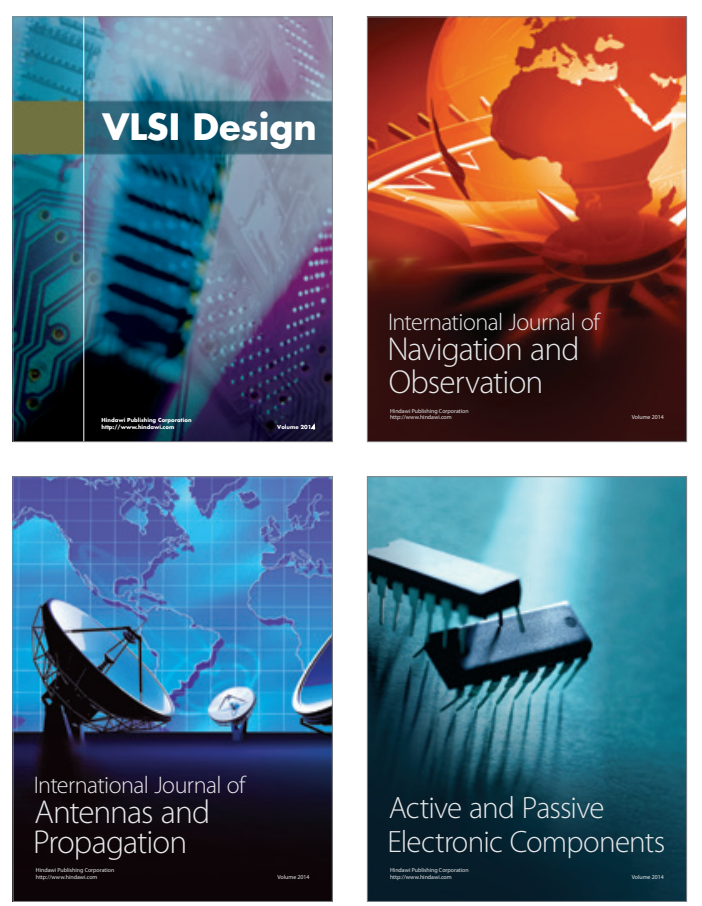
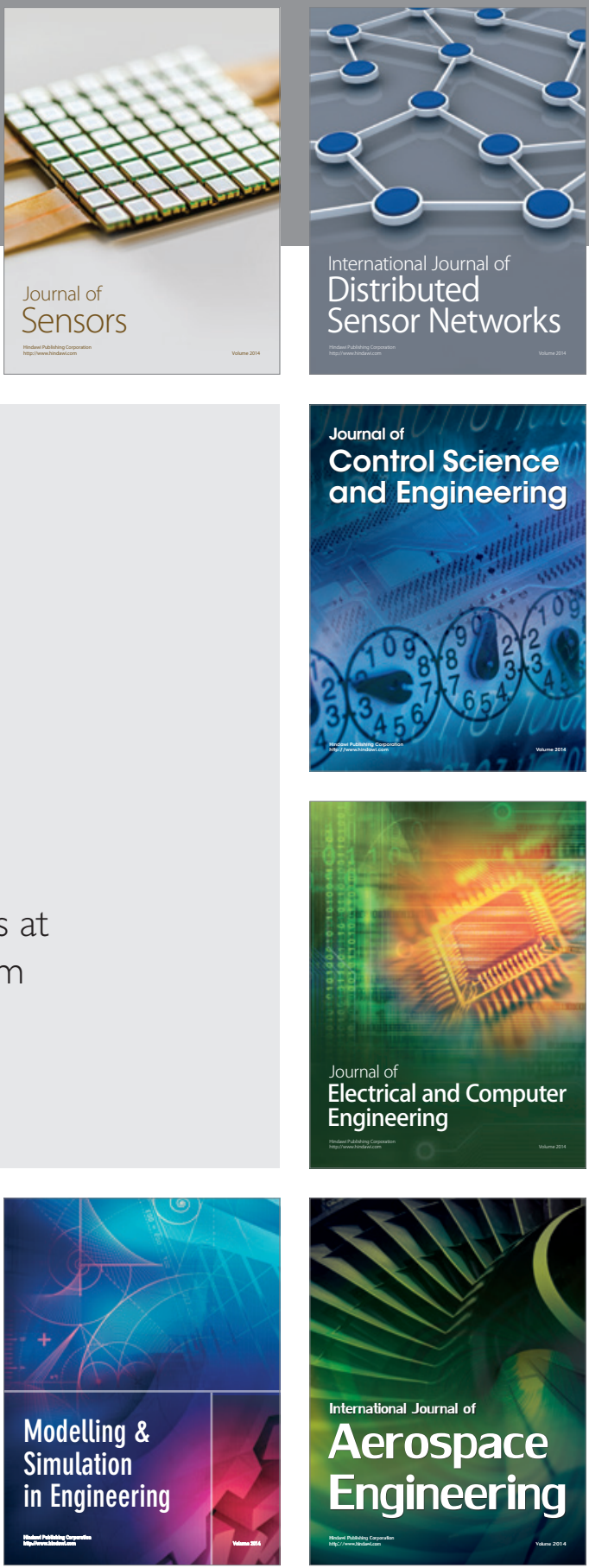

Journal of

Control Science

and Engineering
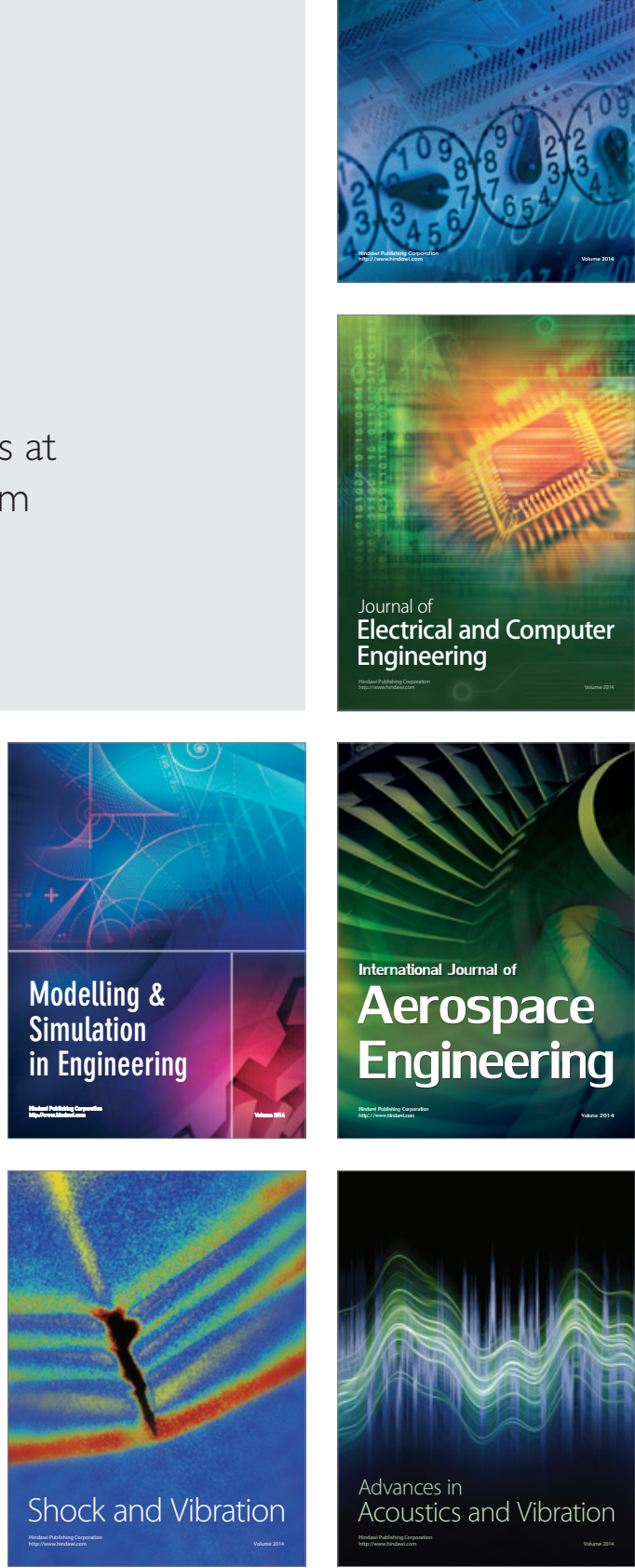